\title{
THE IMPORTANCE OF INTERNATIONAL BUSINESS TO THE STRATEGIC AGENDA OF U.S. CEOS
}

\author{
by \\ Richard C. Hoffman \\ Perdue School of Business \\ Salisbury State University \\ Salisbury, MD 21801 \\ (410) 548-5398 \\ FAX (410) 548-2908 \\ Internet: RCHOFFMAN@SAE.SSU.UMD.EDU \\ and \\ C. Gopinath \\ Department of Business Administration \\ College of Business \& Economics \\ University of Delaware \\ Newark, DE 19716 \\ (302) 831-1780 \\ FAX (302) 831-4196 \\ Internet: GOPINATH@COLLEGE.BE.UDEL.EDU
}

Acknowledgements: We are grateful to William Stoever, Daniel Sullivan, the editor of this journal and three anonymous reviewers who made helpful suggestions on earlier drafts. Both authors contributed equally to the study.

Publication:

Hoffman, R.C. and Gopinath, C. 1994. The Importance of International Business to the Strategic Agenda of U.S. CEOs. Journal of International Business Studies, 25(3): 625-637. 


\title{
THE IMPORTANCE OF INTERNATIONAL BUSINESS \\ TO THE STRATEGIC AGENDA OF U.S. CEOS
}

\begin{abstract}
The growth of international business (IB) and concerns about the relevance of IB research indicate the need for managerial input on the topic. A survey of 108 U.S. CEOs reveals that IB issues are an important part of their strategic agenda. Four types of IB issues are identified which reveal that American CEOs appear to be taking a proactive stance regarding the international arena. The CEOs were also found to hold diverse perceptions of IB issues. The implications of these findings are discussed.
\end{abstract}


During the past decade, U.S. firms faced increased foreign competition. Foreign direct investment grew 18\% per year [U.S. Dept. of Commerce, 1991], and U.S. firms increasingly expanded abroad due to maturing domestic markets. As a result, international competitiveness has become a popular topic among American businesses and political circles. However, American executives are often portrayed as ignoring or reacting to international business issues [e.g., Business Week, 1992]. These developments suggest the need to explore the extent to which international business issues form part of the strategic agenda of major U.S. businesses. Since the strategies of major American firms affect business environments, both domestically and abroad, the strategic agenda of U.S. firms have relevance for non-U.S. firms as well.

Managerial input appears to be lacking in the scholarly treatment of the strategic importance of international business. Executives have been queried on topics such as the skills [Rodrigues and Kaplan, 1989] needed for international operations and the type of education or programs [Ball and McCulloch, 1993, Beamish and Calof, 1989] needed to convey such skills. However, the absence of any recently published survey of managers' opinions concerning the relevance of international business operations to their firms' performance and/or future appears to represent a gap in the current literature. Furthermore, concerns about the relevance of business research in general [Byrne, 1990], and international business [Daniels, 1991] in particular, might be better addressed if we 
seek input from business. Such input might seek to identify some issues of importance to practitioners which might then serve as topics for future research.

The purpose of this investigation is to examine the importance and nature of international business (IB) issues to the strategic agenda of American CEOs. A secondary purpose is to explore the types and nature of IB issues as perceived by CEOS.

\section{THE STUDY}

Since this is an exploratory investigation, the following research questions were developed to provide a focus for the study and data analysis.

\section{What strategic importance do CEOs place on international business issues?}

\section{What types of international business issues are of particular concern to CEOs and how are these issues perceived?}

\section{Survey}

CEOs were selected as the source of data for this study. Although the responsibility for setting the strategic direction of the firm usually rests with the entire top management team, CEOs play a major leadership role in this process [Hegarty and Hoffman, 1987]. CEOs are, therefore, representative of top managers who influence organization strategy.

After a pilot test, questionnaires were mailed to CEOs of the top 500 firms from Business Week's [1990a] list of 1000 most valuable firms, based on market 
capitalization. This list has the advantage of including successful U.S. firms from both manufacturing and service sectors and is, therefore, more representative of American business. To encourage responses, an advisory letter from the Dean of the college sponsoring the study was sent one week prior to mailing the questionnaire with a cover letter.' Three weeks later, a follow-up letter with another copy of the questionnaire was mailed to the sample. Primary data were collected using a two-page questionnaire to assess the strategic concerns of CEOs over the next ten years. Of particular interest to this study were responses to the following: (1) an open-ended question concerning the two or three issues of critical importance for the successful performance of the CEO's firm and (2) CEOs' opinions of the relevance of 10 issues identified by academics [e.g., Lyles, 1990] as relevant to strategic management in the future. The ten issues were represented by 18 items; eight issues were represented by two items (averaged) and two issues were single item measures. Responses to these items were made using a five-point, Likert-type scale (1 = highly relevant to $5=$ not at all relevant).

Secondary data on the demographics of the CEOs and their firms were obtained from published sources [e.g., Business Week, 1990a, 1990b].

\section{Analysis}

Two general types of analyses were conducted to answer the research questions: (a) content analyses of the qualitative data from the open-ended 
question and (b) statistical analyses of the metric data using the appropriate nonparametric (i.e., Spearman's correlation, chi square, and Z tests) and parametric (i.e., T-tests, ANOVAs) tests as reported with the findings.

Content analysis of the open-ended responses was conducted to simplify and classify the qualitative data. In order to reduce the subjectivity of this process, the researchers used the following general procedures for interpreting the data. First, using the same classification methods (described later), each researcher separately analyzed all of the questionnaires. Secondly, the researchers compared the results of their separate analyses and computed a reliability coefficient between them as suggested by Miles and Huberman [1984]. Finally, differences in interpretation/analysis were resolved by reexamining the original responses.2

Using the above procedure, content analysis was conducted of all 283 separate statements made by the CEOs to the open-ended question. These responses were condensed into categories using the method of constant comparison [Glaser and Strauss, 1967]. This method involves comparing the responses to each other and grouping them based on the similarity of their content. ${ }^{3}$ The reliability between the two researchers in classifying the data was .86. Differences in classification were reconciled and the resulting categories reflected the major strategic issues as perceived by the CEOs. Two additional 
content analyses were conducted based on the results of this analysis and are described subsequently along with their respective findings.

\section{FINDINGS}

\section{Survey response and profile}

The data collection procedures resulted in 108 usable responses, representing a $21.6 \%$ response rate. ${ }^{4}$ This response rate compares favorably with prior CEO surveys [e.g., Pearce and Zahra, 1991, reported a $20 \%$ response by CEOs]. A profile of the CEOs surveyed appears in Table 1. A comparison of the responding CEOs with a random sample of non-respondents revealed no significant differences in the CEO or firm mean characteristics depicted in the table. The sample, therefore, appears to represent America's leading firms in services $(50 \%)$ and manufacturing $(49 \%)$ with an average of 5 billion dollars in sales ( $26 \%$ from abroad) and $16 \%$ ROE. The CEOs are males with an average age of 58; the majority (51\%) have graduate degrees and have been with their firms for over 20 years.

Put Table 1 here

\section{1.)What strategic importance do CEOs place on international business issues?}

The responses to the following open-ended question: "In my opinion, the following two or three issues are of critical importance for the successful performance of this corporation into the year 2000 and beyond," were classified 
into sixteen categories. The categories were labeled with names defining their content. Where the category reflected issues defined in the literature, existing terminology was used (e.g., use of "strategy implementation" versus "executing strategy." Collectively, these categories represent a list of issues or an agenda which the CEOs considered to be critically important for the future of their firms. This list is, hereafter, referred to as the CEOs' strategic agenda. The agenda of critical issues is listed in Table 2 in the left hand column with the frequency of mention of each issue and their overall rank to the right, both listed under the column labeled "critical."

\section{Put Table 2 here}

International business (IB) issues were ranked third (based on frequency of mention) among the sixteen critical strategic issues identified. CEOs of thirty-one firms (28\% of the sample) cited a total of 34 issues concerning international competition/operations to be of critical importance. The IB issues represent $12 \%$ of the 283 issues cited by CEOs. To put the emphasis on IB in perspective, IB issues alone were mentioned with the same frequency as nine other strategic issues combined (or $56 \%$ of the issues cited). Thus, the changes in international competition and markets of recent years appears to be having an impact on the strategic agendas of large American firms. 
The critical strategic issues ranked ahead of IB (first and second respectively) were: managing operations efficiently (22.9\% of responses) and the domestic environment $(22.6 \%$, e.g., government policy, the economy, ecology, and social issues). Of the remaining 13 issues cited, each represented less than $10 \%$ of the responses.

The CEOs were also presented with a list of issues deemed important for the future by academicians and were asked to indicate the relevance of these issues for guiding their firm over the next decade. These are hereafter referred to as "relevant" issues. The CEOs' mean responses (and rankings) to these issues are also summarized in Table 2 under the column labeled "relevant." Overall, the 108 CEOs ranked IB issues 6th out of the 10 relevant issues. This suggests that, for those firms which did not cite IB as a critical issue initially, IB is viewed as relevant to their firms but does not appear to be as high on their strategic agendas. CEOs who considered IB issues to be critical (as compared with those who did not) also indicated IB issues to be significantly more relevant in responding to the close-ended items ( $X=1.53$ vs. $2.76, T=7.41, .000)$. This response consistency also offers an indication of the reliability in the CEOs' responses to the two types of questions.

The top five relevant (but not critical) strategic issues cited by CEOs, in descending order were: technology/innovation, strategy implementation, task or industry environment, and leadership. The priority of the issues which CEOs 
ranked as critical bears little resemblance to the priority accorded to those issues considered simply relevant as revealed by the low Spearman's correlation of .22 between the two sets of ranks (see Table 2).

Since strategic processes appear to be affected by CEO [Norburn, 1989] and firm characteristics [Geringer, Beamish and daCosta, 1989; Ginsberg and Venkatraman, 1985], we tested the extent to which our results were generalizable. CEOs' perceptions concerning both the criticality (Chi Square tests) and relevance (T-Tests) of IB issues did not vary significantly due to differences in the CEOs' education, career path or job tenure. However, significant differences were found for two of three firm characteristics (industry, internationalization, and performance). CEOs from manufacturing versus service firms perceived IB issues to be both more critical $\left(X^{2}=8.29, p=.01\right)$ and more highly relevant $(T=3.36, p=$ $.001)$ to their firm's success. Furthermore, firms with a greater level of internationalization (\% of foreign sales) also perceived IB issues to be both more critical $(T=3.95, p=.000)$ to their firm's future. There was a significant relationship $(T=6.12, p=.000)$ between industry and level of internationalization. Service firms $(X=5 \%)$ had significantly $(p \leq .001)$ lower overseas sales than manufacturing firms $(X=26 \%)$. The overall importance of IB issues enabled us to explore the second research question. 


\section{2)What types of international business issues are of particular concern to CEOs and how are these issues perceived?}

Types of Issues. To answer the first part of this question, the CEO responses explicitly reflecting IB issues $(N=34)$ were further content analyzed to identify the types of IB issues of concern to CEOs using the steps described previously and the principle of constant comparison. The reliability of this classification procedure between the two researchers was .80; differences were reconciled prior to finalizing the results. Four types of IB issues were identified in the CEOs' responses and are depicted in Table 3 and described below.

Put Table 3 here

Global Environment (e.g., markets/competition) was mentioned most frequently (41.2\% of IB issues cited). This specific IB issue alone would have tied for 7 th in importance among the 16 critical issues listed on the CEOs' agenda. CEOs viewed the emergence of world markets as the ultimate competitive challenge. Managing internationally was the second most frequently cited (26.5\%) IB issue. In this regard CEOs were concerned with transnational management and developing capabilities for managing foreign operations. International strategies were ranked third (23.5\%) and revealed the need for developing competitive strategies for foreign/global markets. The fourth type of IB issue mentioned was international trade and regulation (8.8\%) which reflects concerns about tariffs and regulation of foreign trade and investment. The types of IB issues identified 
appear to run the gamut from understanding the international environment, to devising strategies and management approaches for operating in such an environment.

Perceptual Dimensions of IB Issues. Concepts such as globalization and international may mean different things to different people [Sera, 1992] especially as they relate to strategy [Sullivan and Baverschmidt, 1991]. The second part of our research question, therefore, sought to identify the different dimensions along which CEOs perceived IB issues. Thus, the IB responses were also analyzed to examine their perceptual dimensions [Dutton, Walton, and Abrahamson, 1989] to determine how they are being perceived by CEOs. The primary analytical schema used were key word analysis and the semantic differential technique. A concept (e.g., IB) can have more than one meaning depending on its context. Key word analysis enables one to determine the various dimensions of a concept's meaning without placing it into mutually exclusive categories [Weber, 1990]. The semantic differential technique is then used to reflect the variation of meaning in each dimension by using polar opposites as anchors. ${ }^{5}$ The reliabilities between the analysis of each researcher using these techniques was .74. After reconciling the differences, this analysis yielded five dimensions along which CEOs appear to perceive IB issues. These dimensions are depicted in Table 4 along with an approximate semantic differential range and sample quotations reflecting the 
varying CEO perspectives on each dimension. Each dimension is described below.

\section{Put Table 4 here}

Orientation (see Table 4) refers to the overall position CEOs appeared to take on IB issues. The CEOs' statements reflected a range of perspectives from international where nationality (domestic vs. foreign) was emphasized to a more global or worldwide perspective. CEO statements also revealed differing levels of specificity regarding IB issues which were critical to their firms. Some issues were stated in highly specific terms while most were expressed in more general terms.

The scope of issues refers to whether the CEOs' international focus was on markets for products or on a broader environment in which to operate. The CEOS differed in their approach or general method for dealing with IB issues, from expressing a learning posture to intentions for taking action. Finally, the theme of cohesion reflects the CEOs' perceptions concerning the overall impact of IB issues on their business environment. Internationalism was perceived to create environments that ranged from more fragmented ones to more integrated ones.

These five perceptual dimensions reveal the diversity and complexity of IB issues. Furthermore, two of these dimensions - orientation and specificity appear quite broad in their applicability because they were reflected in $88 \%$ and 
$100 \%$ respectively of all IB issues cited by CEOs. The other three dimensions were reflected in 59-62\% of the IB issues cited. Given the wide representation of the first two dimensions, they were explored further. The majority of CEOs appear global $(39 \%)$ versus international $(29 \%)$ in their orientation and expressed the IB issues on their agendas in general (62\%) rather than specific (38\%) terms.

\section{DISCUSSION AND IMPLICATIONS}

The findings of this exploratory study begin to fill the gap in the literature by providing CEO input concerning the international business (IB) issues of strategic importance over the next decade. Secondly, this study offers insights into the type of IB issues of concern to CEOs and how these issues may be perceived/interpreted.

The results reveal that all CEOs surveyed perceive international business issues to be relevant for their firms, and for almost a third of the CEOs, IB issues are deemed to be critical to their firm's future success. In these latter instances, IB issues are among the top two or three issues on the CEOs' strategic agenda. Interestingly, CEOs who emphasized the criticality of IB issues also tended to place greater emphasis on technology/innovation $(T=2.45, .02)$ and strategic alliances $(T=2.85, .01)$ than those who did not. These results validate the qualitative findings and underscore the importance, for U.S. as well as non-U.S. firms, of innovation for global competitiveness [Bartlett and Ghoshal, 1989] and the use of alliances to implement them [Contractor and Lorange, 1988]. 
The analysis of the content of IB issues reveals that most American CEOs are proactive in their IB concerns, in contrast to the reactive stance often portrayed in the media when examining the international competitiveness of U.S. firms. This proactive stance is reflected in the strong support for the passage of the North American Free Trade Agreement shown by U.S. CEOs. This should suggest that American firms are interested in participating in competitive global markets rather than in erecting fortresses. Overall, the types of IB issues identified in this study reflect a model of international strategic management which encompasses the environment, strategies, and implementation (managing internationally). Of these, issues relating to the environment (markets and regulation) represented half of all IB issues identified. This suggests that trends in the international/global environment appear to be of critical concern for the successful performance of these firms. This is consistent with the CEOs' overall strategic agenda in which domestic environmental issues (general and industry level) together accounted for the greatest proportion of all 16 strategic issues cited. Thus, this concern for environmental developments is of comparable importance in the international context.

The CEOs' perceptions of IB issues appeared to be comprised of multiple dimensions: orientation, specificity, scope, approach, and cohesion. In particular, the American CEOs revealed a more global vs. fragmented perception of IB issues. Such an orientation has been more often attributed to successful 
European and Asian competitors. Furthermore, the U.S. CEOs revealed a learning- and not merely an action-oriented approach to critical IB issues. These two perceptions may signal that American CEOs of successful firms may be ready to adopt the more comprehensive and patient perspective of some of their more formidable overseas competitors when thinking strategically about future global markets.

In general, the perceptual dimensions reflect the complexity of international business issues as perceived at the strategic level. Two of these perceptual dimensions—scope and specificity—were identified by Dutton, et al., [1989] in their analysis of strategic issues in the domestic context. In addition, our dimensions of approach and cohesion are somewhat analogous to Dutton et al.'s dimensions of actionability and impact respectively. The orientation dimension, however, appears to be unique to IB issues, for it has not appeared heretofore in the strategy literature. Future work in this area might well be complemented by the strategic issues literature to clarify or confirm the dimensions which describe differing perspectives on IB.

A comparison of our findings regarding the CEOs' strategic agenda with a similar agenda proposed by academics [Lyles, 1990] revealed that academics placed greater emphasis on IB issues than did CEOs $(28.9 \%$ vs. $12 \%, Z=3.04, p=$ .002). IB issues appeared first on the academics' agenda followed by restructuring (18\%), strategy implementation (13\%), environmental analysis (9\%), 
technology/innovation (9\%), organization change (9\%), relevant strategy research (7\%), leadership (4\%), and strategic decisions (2\%). In general, all but one issue (relevant strategy research) on the academics' agenda also appeared to be on that of the CEOs. However, the two groups differed regarding the relative importance (based on frequency of mention) of these issues. Thus, the gap between academics and managers might not be as wide as sometimes portrayed [Byrne, 1990].

Our findings need to be interpreted with the following factors in mind. CEOs from successful (market capitalization) major U.S. corporations provided data for this study; therefore, these findings are primarily limited to such a population. Firms which stressed the criticality of IB issues were more internationalized and operated in maturing manufacturing sectors. The IB issues identified here are stated at a fairly broad level due to (a) the research goal of identifying future agenda issues rather than specific plans and (b) to the research method which did not permit probes for more detail. Finally, our conservative approach to classifying strategic issues into categories may have understated the importance of IB issues. Issues were classified as IB if they explicitly contained words such as international, global, worldwide or similar terms. Thus, while issues of competitive strategies, strategic alliances, and innovation pertain to both the domestic and the international context, they were not classified as IB unless stated 
in that context. We do not believe this is a severe limitation, for American CEOs tend to perceive domestic and international arenas separately.

\section{CONCLUSION}

The U.S. accounts for about $23 \%$ of world GDP. The CEOs in this study head major U.S. corporations with over a quarter of their revenues derived from international business. Furthermore, these organizations are increasing their global presence. Consequently, the perspective of these CEOs on IB issues is likely to influence the behavior of their organizations internationally, thereby collectively affecting the worldwide competitive environment. Thus, the findings of this study should be of interest to managers and scholars worldwide.

International business appears to be prominent on the strategic agenda of American corporate leaders. According to our results, CEOs consider the international environment to be especially critical to their future success. By identifying the importance, types, and dimensions of CEO perceptions of IB issues, this study helps provide a managerial perspective regarding IB topics. Managers of both U.S. and non-U.S. firms might use this information to further consider how IB affects their firm's activities. Moreover, non-U.S. managers might gain a little insight into the strategic thinking of their competitors by comparing their own ideas regarding the importance, content, and perceptions of IB issues with those revealed in this study. Finally, academics might use the results of the study to 
investigate IB issues which appear to be of interest and of use to top managers in the future. 


\section{ENDNOTES}

1This technique known as "advanced notification" is widely used in marketing research and has been found to both speed up and increase response rates [Kanuk and Berenson, 1975].

2Differences were reconciled by discussions between the researchers who explained the rationale for their classification. If agreement could not be reached as to appropriate classification of datum, a colleague was presented with the alternative classifications and asked to mediate the decision. The latter occurred on only two occasions.

3This is a well established qualitative analysis technique used to discover themes and patterns in the data. The researcher simultaneously codes and compares the data in order to develop classifications. The method was used to provide a simplified description of the CEOs' responses and not to confirm or refute hypotheses.

${ }^{4}$ Although one respondent per firm creates the possibilities of measurement error, we are concerned with the "average" perceptions of CEOs as a group rather than measuring organizational phenomena. Moreover, we have used both open and close ended questions (multiple methods) to reduce response bias. Furthermore, the apparent representativeness of the sample reduces concern of response bias.

5Further details on these content analysis techniques may be obtained from Osgood, et al., [1975] and Weber [1990]. 


\section{REFERENCES}

Ball, D. A. and W. H. McCulloch, Jr., 1993. The views of American multinational CEOs on internationalized business education for prospective employees. Journal of International Business Studies 24(2): 383-391.

Bartlett, C. A. \& S. Ghoshal. 1989. Managing across borders. Cambridge: Harvard University Press.

Beamish, P. W. \& J. L. Calof. 1989. International business education: A corporate view. Journal of International Business Studies, 22(2): 553-564.

Business Week. 1990a. The Business Week 1000: America's most valuable companies. Special issue.

Business Week. 1990b. The Corporate Elite. Special Issue.

Business Week. 1992. Selling to the world. Special Issue on Reinventing America: $107 \mathrm{ff}$.

Byrne, J. A. 1990. Is research in the ivory tower 'fuzzy, irrelevant, pretentious'? Business Week, (October 29): 62-66.

Contractor, F. \& P. Lorange (Eds.). 1988. Cooperative strategies in international business. Lexington, MA: Lexington Books.

Daniels, J. D. 1991. Relevance is international business research: A need for more linkages. Journal of International Business Studies. 22(2): 177-186.

Dutton, J. E., E. J. Walton \& E. Abrahamson. 1989. Important dimensions of strategic issues: separating the wheat from the chaff. Journal of Management Studies. 26(4): 379-396.

Geringer, J. M., P. W. Beamish \& R. C. daCosta. 1989. Diversification strategy and internationalization: Implications for MNE performance. Strategic Management Journal, 10(2): 109-119.

Ginsberg, A. \& N. Venkatraman. 1985. Contingency perspectives of organizational strategy: A critical review of empirical research. Academy of Management Review, 10(3): 421-434. 
Glaser, B. G. \& A. L. Strauss. 1967. The discovery of grounded theory: Strategies for qualitative research. Chicago: Aldine Publishing Co.

Hegarty, W. H. \& R. C. Hoffman. 1987. Who influences strategic decisions? Long Range Planning, 20(2): 76-85.

Kanuk, L. \& C. Berenson. 1975. Mail surveys and response rates: A literature review. Journal of Marketing Research, 12 (November): 440-453.

Lyles, M.A. 1990. A research agenda for strategic management in the 1990s. Journal of Management Studies, 27(4): 363-375.

Miles, M. B. \& A. M. Huberman. 1984. Qualitative data analysis. Newbury Park, CA: Sage.

Norburn, D. 1989. The chief executive: a breed apart. Strategic Management Journal, 10(1): 1-15.

Osgood, C. E.; W. H. May \& M. S. Miron. 1975. Cross-cultural universals of affective meaning. Urbana, IL: University of Illinois Press.

Pearce, J. A. \& S. A. Zahra. 1991. The relative power of CEOs and boards of directors: Associations with corporate performance. Strategic Management Journal 12(2): 135-13.

Rodrigues, C. A. \& E. Kaplan. 1989. Executive perceptions of international skills needed by MNEs and college course offerings: Do they match? Issues in International Business, 5(2): 16-19.

Sera, K. 1992. Corporate globalization: A new trend, The Academy of Management Executive, 4(1): 89-96.

Sullivan, D. \& A. Bauerschmidt. 1991. The "basic concepts" of international business strategy: A review and reconsideration. Management International Review, Special Issue: 111-124.

U. S. Dept. of Commerce. 1991. Survey of current business. Washington, D.C.: U.S. Dept. of Commerce.

Weber, R.P. 1990. Basic content analysis, Newbury Park, CA: Sage. 
TABLE 1

STATISTICAL PROFILE OF CEOS AND THEIR FIRMS

$(N=108)$

\section{CEO CHARACTERISTICS}

Age:

Mean: 58 yrs (Range: 40-79)

Education:

No College

Bachelor's

$6 \%$

MBA

$42 \%$

Other Grad.

$25 \%$

Degrees

$26 \%$

Career Path:

General Management/Founder $\quad 13 \%$

Finance/Accounting $\quad 27 \%$

Marketing, Sales, Merchandising $\quad 32 \%$

Production/Engineering/R\&D 24\%

Other

$4 \%$

Tenure with Co:

Mean: 23.1 yrs (Range: 1-54)

CEO: Mean: 7.0 yrs (Range: 1-30)

\section{FIRM CHARACTERISTICS}

Industry:

Manufacturing:

Capital Goods

Chemicals

Consumer Products

Food

Office Machines

Other

$11.1 \% \mathrm{a}$

$9.2 \%$

$9.2 \%$

$6.4 \%$

$8.3 \%$

$4.6 \%$

Services:

Banking \& Finance

Health Care

$11.1 \%$

Telecommun.

Transportation

Utilities \& Power

Other

SALES:

Less than $\$ 500$ million: $\quad 9 \%$

$\$ 501$ million - 7 billion: $\quad 69 \%$

$\$ 7.1$ - 13 billion: $\quad 12 \%$

$\$ 13.1$ - 20 billion: $\quad 7 \%$

Over $\$ 20$ billion: $\quad 3 \%$

ROE:

Mean: $15.87 \%$

$6.4 \%$

$5.5 \%$

$4 \%$

$17.5 \%$

$5.5 \%$

$\underline{\%}$ of Foreign Sales

0-10\%: $\quad 47 \%$

11-25\%: $\quad 13 \%$

26-50\%: $\quad 19 \%$

Over 50\%: $\quad 7 \%$

Not Available: $\quad 14 \%$

Sources: Business Week, Special Issues, The Business Week 1000 and The Corporate Elite, 1990.

aDoes not add to $100 \%$ due to rounding. 


\section{Table 2}

Strategic Business Issues for The Nineties:

CEO Perspectives

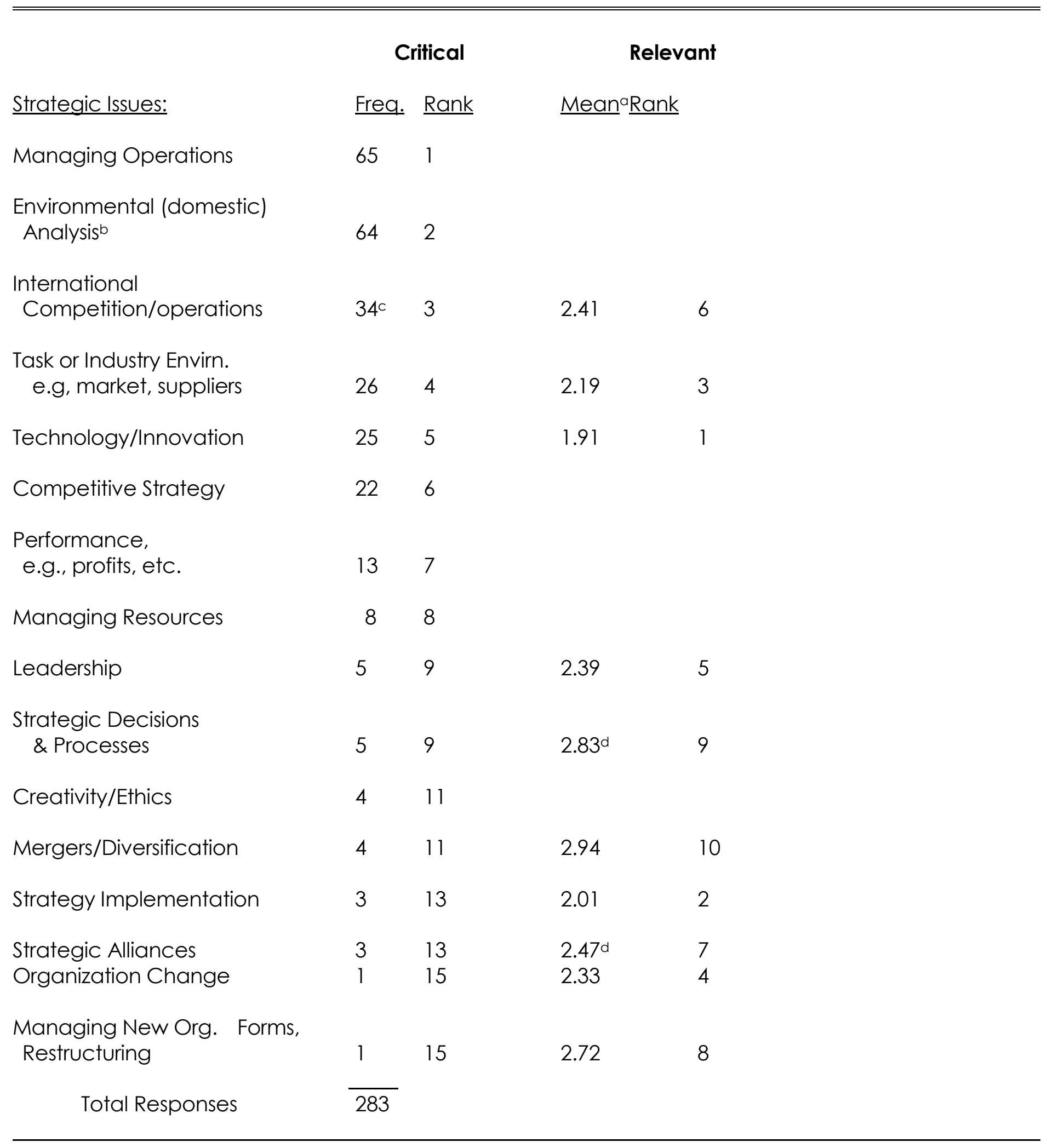




\section{Table 2 -- Continued}

a Means based on scale where: 1=Highly relevant, 2=very, 3=somewhat, 4=not very, 5=not at all.

b This category was more broadly defined by CEOs; below, it has been divided into two subsections to permit direct comparisons with data from academics which was more narrowly defined as " government policy."

\begin{tabular}{llrr} 
& \multicolumn{3}{c}{ CEO } \\
\cline { 2 - 4 } Frea. & $\%$ & Rank \\
b.) Eovernment Policy & $(33$ & 11.7 & $3)$ \\
& $(31$ & 10.9 & $4)$
\end{tabular}

c Three of the 31 CEOs each explicitly cited two distinct IB issues among the three issues critical for their firm in the future.

a Means are based on response to one item; all other means reflect responses to two related items. 
Table 3

Specific Types of International Business Issues of Concern to CEOS

\author{
$\%$ of All IB Issues \\ Mentioned ( $N=34$ IB Issues)
}

Global Environment

Managing Internationally

International Strategies

International Trade \& Regulation
$41.2 \%$

$26.5 \%$

$23.5 \%$

$8.8 \%$

$100.0 \%$ 


\section{Table 4}

Perceptual Dimensions of the Critical International

Business Issues Identified By CEOs

Dimensions of IB

$\underline{\text { Range }}$

Orientation

Global

International

"Competitive strategies for global

markets"

"Developing foreign

markets"

"Being able to meet

competition from

abroad"

General <

Specific

"Global orientation"

"Organization, structure, and information systems

to support leading market share in Asian,

European and NA markets"

Scope

Markets

"Competing in world markets"

"Operate effectively in a dynamic global environment"

\section{Approach}

Action

"Establishing solid world-wide competitive advantage - design, cost, quality"

\section{Learning}

"Developing capability to manage foreign operations"
"One world market. Boundaries become Transparent"
"Understanding how to operate in the major trade blocs (EC, North Amer. and Pacific ASEANJapan)

aSemantic differential reflecting the range of perspectives revealed in CEO responses. Direct CEO quotations also provide examples of range. 